\title{
LIXO URBANO, POPULAÇÃO E SAÚDE: UM DESAFIO
}

SILVA, Lucimara ${ }^{1}$

MELLO, Silvio de Paula ${ }^{2}$

RESUMO: O crescimento demográfico causou um aumento na quantidade de resíduos. A população das cidades geralmente consome muito mais do que necessita e muito desses produtos são lançados no ar, na água e no solo provocando uma poluição irreversível. Esses compostos entram na cadeia e alimentam, atingindo a espécie humana, prejudicando a saúde da população. Não há como não produzir lixo. No entanto, podemos reduzir a produção reutilizando, sempre que possível os materiais recicláveis, através da coleta seletiva. Essa atividade proporciona redução expressiva de resíduos sólidos que seriam jogados no meio ambiente, e ainda geram renda para aqueles que efetuam esse trabalho como colaboradores da limpeza das cidades.

Palavras-chave: Crescimento demográfico. Saúde. Coleta seletiva.

SUMMARY: Population growth has caused an increase in the amount of waste. The population of cities typically consumes much more than you need and much of these products are released into the air, water and ground causing an irreversible pollution. These compounds entering the string feeds reaching mankind damaging people's health. There is no way not to produce garbage. We can, however, reduce that production reusing, whenever possible the recyclable materials through selective collection. This activity provides dramatic reduction of solid waste that would be played to the environment, and also generates income for those who perform this work, making them also collaborators of cleaning of cities.

Keywords: Population growth. Health. Selective collection.

\section{INTRODUÇÃO}

Durante mais de quatro séculos a vida brasileira esteve muito mais relacionada com o campo do que com a cidade. O Brasil era um país rural, e as poucas cidades que existiam se organizavam em função da produção realizada no campo. Além da produção da zona rural, incrementou-se a produção de bens materiais na zona urbana, e a quantidade da população urbana começou a crescer (LINHARES; GEWANDSZNAJDER; 2009). Os mesmos autores citam que durante a segunda metade do século IX e durante todo o século XX ocorreu um intenso processo de urbanização da população mundial. Com o rápido e, em muitos casos, desordenados crescimento das cidades, em países desenvolvidos e em desenvolvimento, elas passaram a acumular problemas ambientais. Uma das maiores agressões ao meio ambiente são os resíduos sólidos de áreas urbanas, popularmente chamados de lixo.

Provavelmente, ele é um dos maiores responsáveis pela poluição ambiental, talvez seja a principal gênese da poluição ambiental ( SCARLATO; PONTIN, 1992). Até o início do

\footnotetext{
${ }^{1}$ Bacharel em Ciências Biológicas - FE - Faculdade de Filosofia Ciências e Letras.

${ }^{2}$ Professor Dr. em Genética e Evolução (UFSCar) - FE/FAFRAM - email: spmello@ feituverava.com.br
} 
século XX, o lixo humano era biodegradável e reciclável, ou seja, largamente reaproveitado pelas pessoas, e os restos de alimentos eram utilizados como comida para os animais, as madeiras que sobravam de uma construção eram convertidas em lenha para o aquecimento das casas e as colchas de retalho eram feitas das sobras de tecidos de confecção artesanal (ADAS, 2002).

Para Braga et al. (2002), a poluição é uma alteração indesejável nas características físicas, químicas ou biológicas da atmosfera, litosfera ou hidrosfera que cause ou possa causar prejuízo à saúde, à sobrevivência ou às atividades dos seres humanos e outras espécies ou ainda, deteriorar materiais.

Segundo Adas (2002), o crescimento demográfico, combinado com o desenvolvimento industrial, as mudanças dos hábitos de consumo e a melhoria da qualidade de vida causaram um aumento na quantidade de resíduos, assim como alteraram suas características. Esse autor corrobora dizendo que, nos dias atuais, infelizmente, o cidadão é, antes de tudo, um consumidor. E quanto maior a renda, mais consumidor será o cidadão, e mais lixo vai gerar. E isso representa um grande problema ambiental, pois a maioria das pessoas, preocupadas tão somente com o seu conforto, consomem cada vez mais sem qualquer preocupação com o destino final do lixo.

No Brasil se produzem cerca de 242 mil de toneladas de lixo por dia e dessa quantidade, 90 mil toneladas são lixo domiciliar, dados da Fundação Padre Anchieta (2001).

Os alimentos são comprados em supermercados (que estão sempre abastecidos), consumidos, e os seus resíduos são despejados nas lixeiras, que funcionam como "sumidouros mágicos" dos detritos. Os metabólitos do megaconsumo humano são convenientemente escondidos dos olhos das suas populações, à exceção daqueles miseráveis que vivem dessa sobras, autênticos detritívoros humanos (DIAS, 2004).

Braga et al.(2002), comentam que os efeitos da poluição podem ter caráter localizado, regional ou global. É importante um esforço conjunto e sem precedentes para que se possa conhecer esses efeitos e controlá-los de modo eficaz. Para ele, o fato de não ser possível consumir a matéria até sua aniquilação implica a geração de resíduos em todas as atividades dos seres vivos, resíduos esses indesejáveis a quem os eliminou, mas que podem ser reincorporados ao meio ambiente, para serem posteriormente reutilizados no processo que chamamos de reciclagem.

A forma como o lixo é produzido, sua composição, a quantidade de reaproveitamento e o destino final indicam o desenvolvimento e a cultura de uma sociedade, já que a produção e deposição final do lixo é um problema mundial, destacando que os aterros sanitários ocupam grandes áreas e se tornam inutilizáveis após seu esgotamento (ADAS, 2002). 
E muitos já não têm mais capacidade para tantos dejetos, alerta a Fundação Padre Anchieta (2001).

Esse trabalho tem como objetivo mostrar o que se pode fazer, ganhar e aprender com a reciclagem do lixo urbano. Estimular a mudança de atitudes e a formação de novos hábitos com relação à utilização dos recursos naturais, e favorecer a reflexão sobre a responsabilidade ética do ser humano com o próprio planeta como um todo, despertando nos colaboradores uma consciência ambiental e responsabilidade social.

\section{ATIVIDADES HUMANAS E PRODUÇÃO DE LIXO}

Para compreendermos o acentuado aumento e a diversificação na produção de lixo no mundo, precisamos compreender primeiro a dependência do desenvolvimento econômico aos mecanismos de mercado que segundo ele, além de significar uma resposta às necessidades materiais do homem, os produtos adquiridos cada vez mais funcionam como indicadores de suas realizações e de sua posição social. Por estranho que pareça, o lixo de cada um pode ser considerado hoje como mais um desses indicadores (SCARLATO; PONTIN, 1992).

Vivemos em uma sociedade cada vez mais industrializada e urbana, consequentemente menos pessoas vivendo na área rural (ADAS, 2002).

Para manter a rotina de consumo nas cidades, ecossistemas naturais são destruídos para ceder espaços à agricultura e pastagens para gado. Além de ameaçar o equilíbrio da natureza pela forma como utiliza os recursos naturais, há outra ameaça causada pelo crescimento desenfreado da população humana, em condições de extrema desigualdade social (LAURENCE, 2005).

Andrade et al. (2007) cita que as diversas atividades humanas geram resíduos e produtos que não têm utilização imediata e que se acumulam no ambiente. Esse material constitui o lixo, que é um dos maiores problemas das sociedades modernas. Nas duas últimas décadas, a quantidade de lixo urbano tem aumentado e sua composição tem-se modificado. $\mathrm{O}$ lixo das residências, além de restos de alimentos e material reciclável (vidros, latas, papel e plásticos), apresenta grande número de materiais que podem causar danos aos ecossistemas e riscos à saúde humana.

Para Lutzenberger (1992), antes das interferências irracionais do homem, cada local tinha a cobertura vegetal que convinha às condições do lugar, pois esta cobertura era resultado da seleção natural implacável, agindo através das longas eras da história da evolução. $\mathrm{O}$ equilíbrio global entre os efeitos parciais dos sistemas está em interação recíproca e em 
interação com a atmosfera e a hidrosfera. Mas o homem está hoje alterando ou degradando cada um dos sistemas, e acabará alterando o equilíbrio global.

Toda e qualquer alteração ocorrida no ambiente, que provoque desequilíbrio e prejudique a vida, é considerada poluição ambiental. A poluição ambiental pode ser causada tanto pela liberação de energia quanto pela liberação de matéria no ambiente. O aumento da quantidade de substâncias não-biodegradáveis no meio ambiente tem trazido sérios problemas aos ecossistemas (LOPES; ROSSO, 2005). Ressaltam ainda ressaltam que a pessoa é responsável por cerca de 3,6 quilogramas de lixo por dia. Algumas soluções têm sido proposta, mas há muitas outras que podem e devem surgir. Por isso em algumas cidades as prefeituras têm feito a coleta seletiva, facilitando o tratamento do lixo urbano e sua reciclagem. Nesses casos, separa-se a matéria orgânica que se decompõe facilmente (como restos de comida) de outros materiais, como vidro, metal, papel e plásticos, que podem ser reciclados, isto é, reaproveitados na fabricação de novos produtos.

Detritos orgânicos ou inorgânicos são considerados poluentes quando provocam mudanças nas propriedades físicas, químicas ou biológicas do ambiente onde estão sendo introduzidos, e tais mudanças acontecem porque os poluentes são colocados em quantidades excessiva ou simplesmente porque o meio não se encontra adaptado à presença deles (PAULINO, 2001).

O lixo além de ser um problema ambiental no Brasil também pode ser considerado um problema econômico (gastos para remoção de 240 toneladas diárias. Um simples ato de jogar um papel na rua acarreta a contratação de milhares de garis, produção de toneladas de lixo e riscos à saúde humana). O lixo urbano parece ser um problema sem solução. Todas as forma de tratamento atuais geram algum outro problema. Apesar das inúmeras tecnologias diferentes desenvolvidas para processar o lixo, a melhor saída parece estar ligada a mudança de comportamento das pessoas. A melhor forma de auxiliar com o lixo é a diminuição do mesmo (INFOESCOLA, 2009).

Infelizmente, o crescimento industrial e populacional não foi acompanhado por uma tecnologia de remoção, transformação e reaproveitamento dos detritos resultantes da intensa atividade humana. Caso houvesse boa vontade, poderíamos minimizar o efeito causado pelos resíduos da vida moderna com alguns cuidados (BLINDER et al., 1992).

\section{ASPECTOS SOBRE SAÚDE}

Saúde e meio ambiente sempre estiveram intimamente relacionados. Sem ter a pretensão de descrever em detalhes essa relação observa-se, ao longo do tempo, que o papel 
atribuído ao meio ambiente dentro do processo saúde-doença tem se modificado, havendo períodos em que sua importância era enfatizada, e outros em que praticamente negou-se sua participação neste processo. As condições gerais de saúde são aquelas que dizem respeito a toda uma comunidade. Compreendem as características topográficas da região em que se vive, com suas variações climáticas e sazonais, a natureza do solo, a pureza da água e do ar, além de levar em consideração a salubridade das residências, o tipo de indumentária habitualmente usada, a qualidade da alimentação, a existência ou não de saneamento básico na área, de serviços assistenciais de saúde (SOARES, 1994). Se um planejamento global de saúde puder atender democraticamente, com objetivos e diretrizes metodológicas amplas e humanitárias, a todas as camadas da população, notadamente as mais carentes, a comunidade poderá contar com um poderoso instrumento de transformação social, capaz de contribuir para a melhoria da qualidade de vida de um País.

Para compreender esse problema que atinge inúmeras pessoas e famílias, sobretudo de baixa renda, é preciso considerar, inicialmente, a falta de uma legislação urbanística atenta às limitações físicas das áreas de encostas nas cidades ou o fato de que, quando existe, ela não consegue ser colocada em prática de forma eficaz (ADAS, 2002).

Soares (1994) cita que é possível dizer que a degradação do meio ambiente pelo homem tem sido pior principalmente nos países mais pobres, uma vez que neles a urbanização vem ocorrendo de uma forma mais rápida. A vivência cotidiana molda padrões comportamentais habituais, e nesse sentido, o morador urbano tem na maioria das vezes, situações diárias vivenciadas de forma repetitiva, o que produz uma espécie de máscara destas situações no contexto. Muita pesquisa tem demonstrado que deficiências nutritivas e até a poluição ambiental provocam a ocorrência de malformações embrionárias. Algumas estatísticas mostraram incríveis percentagens de defeitos congênitos entre crianças nascidas em cidades ou localidades com altos níveis de poluição atmosférica. Muitos dos produtos utilizados pelo homem moderno passaram a ser lançados intempestivamente por ele no ar, nas águas ou no solo, provocando uma poluição irreversível, e de uma permanência muito longa no ambiente. Dessa forma, tais compostos ou elementos entram nas cadeias alimentares e passam às plantas, depois aos animais herbívoros, mais tarde aos carnívoros e, finalmente, atingem a própria espécie humana.

Ao se considerar a ação de poluentes sobre a saúde humana, porém, deve-se ter sempre em mente não apenas suas conseqüências imediatas, mas também aquelas que podem manifestar-se a longo prazo, decorrente do acúmulo do composto no organismo ao longo do tempo. No começo, ele pode até não causar danos ou provocar danos quase imperceptíveis e 
reversíveis, depois, os problemas vão se tornando cada vez mais graves e podem se transformar em irreversíveis (SCARLATO; PONTIN, 1992).

Segundo dados, uma indústria em uma cidade no interior de São Paulo recebeu multa pelo odor excessivo exalado pela mesma. Os moradores reclamaram que o odor de resina provoca dores de cabeça e de estômago, náuseas e ardência nos olhos e na pele (COISSI, 2009).

\section{DESTINO FINAL DO LIXO}

De acordo com Vessentini e Vlach (2002) nos dois últimos séculos a humanidade destruiu o meio natural, confiante na idéia de que a natureza é infinita. Pensava que todos os danos seriam naturalmente corrigidos. Hoje sabemos que muitos dos graves danos causados à biosfera não se corrigem por si. E, o que é pior, se continuarem ocorrendo em grande escala, pode ameaçar a sobrevivência do ser humano.

Está claro que a espécie humana não poderá continuar por muito tempo com a sua cegueira ambiental e com sua falta de escrúpulos na exploração da natureza. Tudo tem seu preço, e, quanto maior o abuso, maior será o preço (LUTZENBERGER, 1992).

Dias (2004) ressalta que a capacidade de suporte para a vida humana e para a sociedade é complexa, dinâmica e varia de acordo com a forma segundo a qual o ser humano maneja os seus recursos ambientais. O preço de morar em uma cidade é um estado constante de ansiedade. As cidades são os locais onde o homem produz o seu maior impacto sobre a natureza.

O lixo urbano, muitas vezes, é responsável pelos impactos ambientais que mencionamos. Milhões de toneladas de lixo doméstico e resíduos industriais são produzidos e vazados em áreas urbanas ou de periferia, com inevitáveis riscos para a saúde humana. Em muitos lugares, formam-se montanhas de produtos descartados, em torno das quais se desenvolvem comunidades que vivem de um verdadeiro "garimpo" de materiais que podem ser vendidos e reciclados, dali retirando o seu alimento (SOARES, 1994).

Entre os impactos ambientais negativos que podem ser originados a partir do lixo urbano produzido estão os efeitos decorrentes da prática de disposição inadequada de resíduos sólidos em fundos de vale, às margens de rua ou cursos d'água. Essas práticas habituais podem provocar, entre outras coisas, contaminação de corpos d'água, assoreamento, enchentes, proliferação de vetores transmissores de doenças, entre outros. Some-se a isso a poluição visual, mau cheiro e contaminação do ambiente (MUCELIN, BELLINI, 2008). 
A produção e deposição final do lixo é um problema mundial, sobretudo nas grandes cidades, que concentram um maior número de habitantes numa área. Essas áreas transformam-se em criadouros de insetos e roedores, agentes transmissores de inúmeras doenças contagiosas, além disso, nessas condições ocorre a penetração do chorume no solo, que acaba poluindo o lençol d'água subterrâneo (ADAS, 2002).

De acordo com Araujo e Günther (2007), a utilização de caçambas metálicas em áreas públicas para acondicionar resíduos da construção e demolição tem sido incrementada, em cidades brasileiras, contribuindo para o adensamento do mobiliário urbano e modificando a paisagem urbana. Este equipamento é utilizado para confinar os resíduos de modo a impedir sua dispersão no ambiente, facilitar sua coleta e transporte e evitar a exposição de moradores e transeuntes. A despeito dessas vantagens, as caçambas representam um perigo ao ambiente e à saúde pública, pois os resíduos, geralmente considerados inertes, depositados nesses equipamentos contêm materiais de diversas formas e tamanhos, podendo conter resíduos perigosos como tintas, solventes e fibras de amianto, lâmpadas fluorescentes, pilhas e baterias.

Ratificando o parágrafo anterior, essas caçambas são utilizadas para acondicionar resíduos de construção e demolição, mas nem sempre é o que acontece, pois muitas vezes são utilizadas para outros fins servindo de depósito para descarte de lixos utilizados pela população (Figura 1).
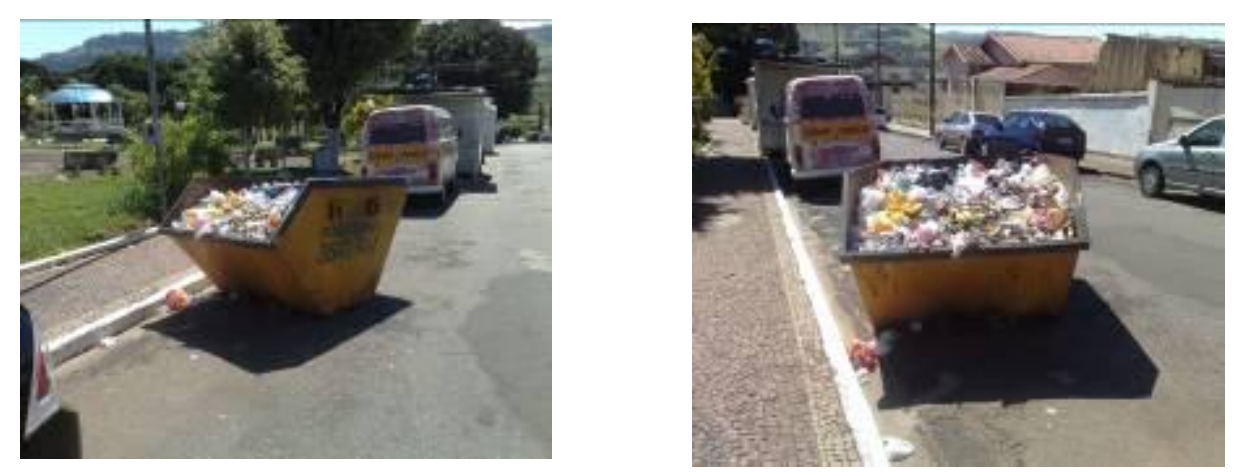

Figura 1. Caçambas metálicas contendo lixo.

Em alguns locais, o lixo é lançado em um terreno baldio, formando um lixão (LINHARES; GEWANDSZNAJDER, 2005).

Próximo a estes terrenos estão localizadas muitas residências, onde os moradores ficam expostos ao lixo que é descartado inadequadamente tornando uma ameaça à população (Figura 2). 


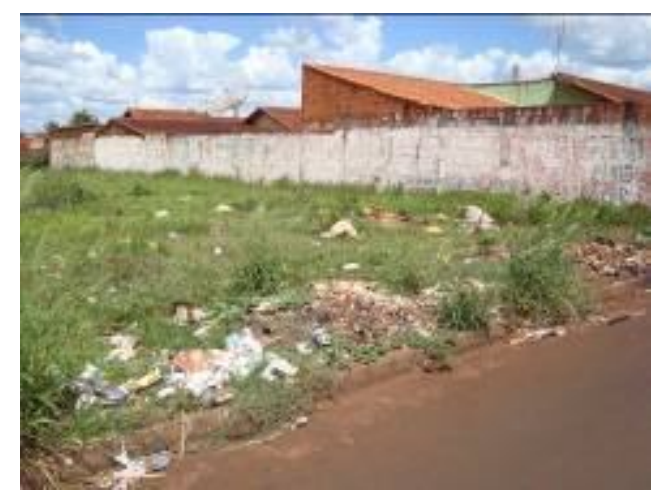

Figura 2. Terreno baldio.

Essas áreas transformam-se em criadouros de insetos e roedores, agentes transmissores de inúmeras doenças contagiosas, além disso, nessas condições ocorre a penetração do chorume no solo, que acaba poluindo o lençol d'água subterrâneo (ADAS, 2002).

Como se não bastasse, muitas pessoas além de jogar o lixo fora dos coletores e próximos a rodovias que dão acesso a bairros e faculdades (Figura 3), ainda ateiam fogo aos resíduos causando uma grande fumaça poluidora do ar, tornando assim um risco aos passageiros dessa rodovia.
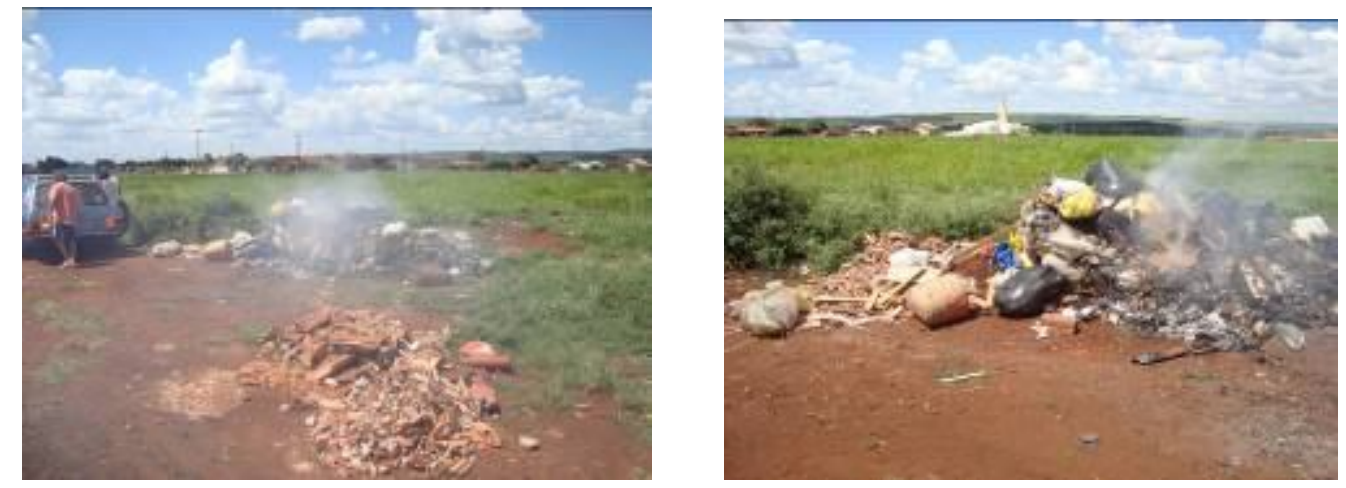

Figura 3: Lixo consumido pelo fogo próximo à rodovia.

Além disso, as populações de baixa renda passaram a explorar esses lixões recolhendo restos de comida, objetos e outros itens, o que coloca em risco sua própria saúde (LOPES; ROSSO, 2005).

Algumas prefeituras disponibilizam caçambas para que possa ser depositado o lixo da população, mas mesmo assim os moradores não despejam devidamente os detritos, ficando a maior parte do lixo fora dos coletores (Figura 4). 


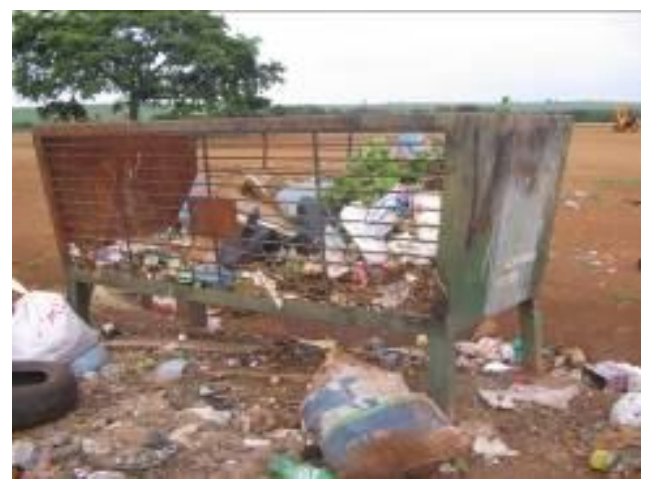

Figura 4: Coletor de resíduos.

Existem várias alternativas para o destino final correto dos resíduos urbanos. Hoje, em muitas cidades, já existem cooperativas de reciclagem formadas pela própria população, e estas contam com o apoio dos moradores para que o lixo não seja apenas um material descartado, mas sim reciclado, reaproveitado e reutilizado.

Nas cidades que adotam o sistema de coleta seletiva de lixo, as pessoas devem separar os diversos tipos de material (metais, plásticos, vidros, sobras de alimentos) e colocar cada um em coletores específicos. O material a ser reciclado é recolhido e encaminhado para usinas de reciclagem (LINHARES; GEWANDSZNAJDER, 2005).

Em algumas cidades, os coletores de determinada cooperativa passam pelos bairros recolhendo todo o material guardado pela população. Eles doam "bags" para que possam ser utilizados como recipiente dos resíduos acumulados, e no dia marcado para a coleta os moradores entregam os "bags" cheios e recebe outro vazio para uma nova coleta. Todo o material é colocado em um caminhão que depois levará para um depósito onde será feita a separação dos resíduos e finalmente serem enviados para empresas de reciclagem (Figuras 5). Algumas cooperativas não recolhem resíduos orgânicos, somente resíduos secos.
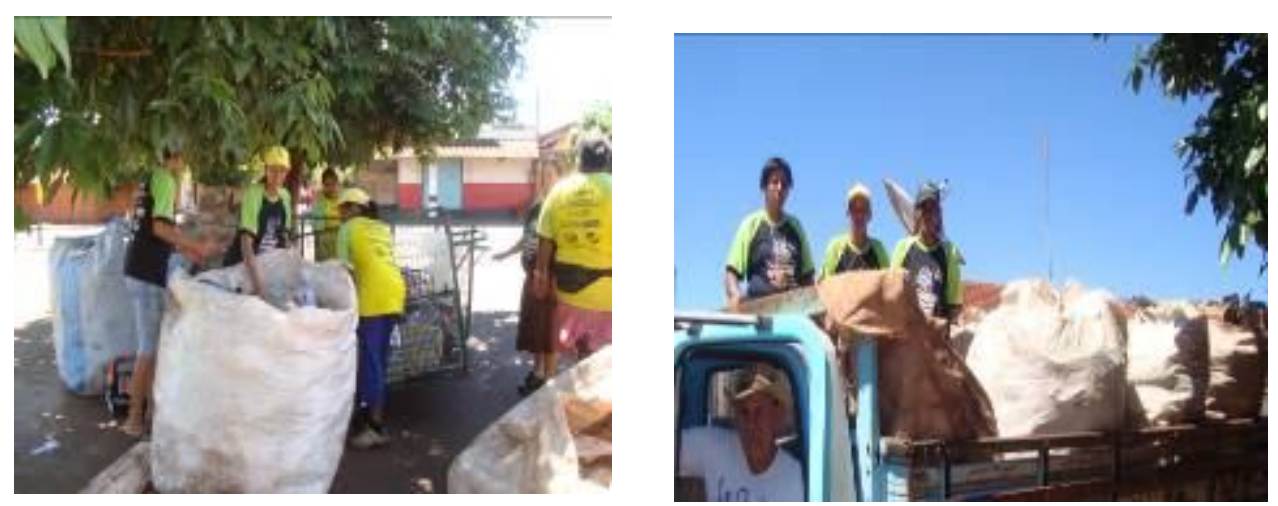

Figura 5: Catadores recolhendo bags.

Depois de reciclado esses resíduos retornarão à população sob a forma de novos produtos como, por exemplo, o papel, e poderão ser utilizados novamente.

Um número incontável de pessoas à margem do mercado de trabalho e que se 
encontram envolvidas nas atividades relacionadas a coleta seletiva de lixo e sua comercialização, tem obtido com essas atividades recursos financeiros ou seja o mínimo para suprir suas necessidades básicas com dignidade como seres humanos. Essas atividades proporcionam redução expressiva nas toneladas de resíduos sólidos que seriam jogados ao meio ambiente. A reciclagem de lixo possibilita economia de energia, água, matéria prima. Quando se descarta os resíduos sólidos sem controle, estes poluem o meio ambiente, contribui para o efeito estufa, o aquecimento global, a poluição dos lençóis freáticos, dos rios e provocam emissão de metano (OLIVEIRA, 2009). Coletando e reciclando materiais descartados aleatoriamente, os catadores de lixo tornam-se também agentes ambientais e contribui com a limpeza da cidade. As políticas governamentais, as parcerias com a sociedade, e com instituições públicas e privadas são fundamentais ao desenvolvimento de cooperativas de reciclagem. Muitas empresas poderiam contribuir se fosse parceira, com o apoio a iniciativas básicas, como proposta de implantação de cooperativas, divulgação do trabalho desses catadores, que se organizados, e com a contribuição de parcerias, contribuiriam para o desenvolvimento do município apoiando o gerenciamento da coleta seletiva.

Existem diversas soluções que podem colaborar na manutenção da qualidade do meio ambiente: evitar sacolas plásticas de lojas ou supermercados para carregar compras, sempre que possível utilize sua própria sacola, bolsa ou mochila; sempre que possível, evite produtos descartáveis; não jogue lixo na rua; não joguem no lixo roupas, brinquedos antigos, utensílios de casa ou sapatos, em muitos casos podem ser doados ou restaurados; separe vidros, jornais, revistas e embalagens de papel para vender ou dar a catadores ou encaminhar para a coleta seletiva, se houver em sua cidade (LINHARES; GEWANDSZNAJDER, 2005).

Analisar um problema não é olhar para ele, mas estar dentro e fora ao mesmo tempo, assim, a visão aumenta na percepção, permitindo enxergar as causas que devem ser encaradas como fator predominante. Não basta trabalhar apenas nos efeitos, a causa é a base de qualquer efeito. A iniciativa e o envolvimento são os primeiros passos, sendo, o comprometimento a realização (NASCIMENTO, 2007).

\section{CONSIDERAÇÕES FINAIS}

Nos últimos tempos o crescimento populacional tem contribuído para agravar a situação da condição ambiental. Alguns anos atrás, produtos que fossem utilizados pelas famílias eram reutilizados quando havia sobras. Hoje nem sempre isso acontece, pois o homem muitas vezes nem se dá conta da quantidade de resíduos que lança fora no seu dia a 
dia, tornando-se um grande consumidor e respectivamente um grande poluidor devido as suas atitudes de descarte dos resíduos consumidos.

Sabe-se que esses resíduos quando descartados de forma incorreta em lixões, terrenos baldios, caçambas utilizadas para depositar entulhos da construção civil e em outros lugares que não seja apropriado para acolhê-los, pode atrair vetores de várias doenças sendo muita delas transmissíveis. Ainda acaba por chamar a atenção de pessoas que com condições precárias, aproveitam-se desses resíduos que muitas das vezes se encontram pela metade ou em situações até razoáveis, tornando-se produto de consumo para os mesmos.

Hoje existem diversas maneiras de dar um destino final adequado aos resíduos que consumimos e que geralmente é chamado de lixo, como exemplo juntar todo o resíduo orgânico e a partir dele obter adubo orgânico utilizado pela lavoura na produção alimentícia. Ou ainda fazer o que se conhece por coleta seletiva onde todo o lixo seco (papelão, vidro, alumínio, plástico) que é inutilizado pela população é separado, cada um de acordo com o seu material, e depois entregue aos catadores ou até mesmo cooperativas que fazem esse trabalho para reciclar esse material e transformá-lo em novos produtos.

A coleta seletiva além de servir de fonte de renda para esses colaboradores, ainda ajudam manter o ambiente das cidades limpas, evitando que esses lixos se acumulem em locais inadequados provocando o entupimento de esgotos das vias públicas e evitam o mau cheiro dos terrenos baldios, caçambas coletoras e outros lugares.

Assim se cada um se tornar responsável pelo seu lixo, com certeza estará fazendo sua parte para melhorar a qualidade do meio ambiente.

\section{REFERÊNCIAS}

ADAS, M. Geografia: os impasses da globalização e o mundo desenvolvido. 4. ed. São Paulo: Moderna, 2002.

ADAS, M. Geografia: noções básicas de geografia. 5. ed. São Paulo: Moderna, 2006. ANDRADE, M. H. de P. et al. Ciência e vida: ambiente, transformações e diversidade. Belo Horizonte: Dimensão, 2006.

ARAUJO, J. M. de; GÜNTHER, W.M.R. Caçambas coletoras de resíduos da construção e demolição no contexto do mobiliário urbano: uma questão de saúde pública e ambiental. Saúde e Sociedade v.16, n.1, p.145-154, jan-abr 2007. p. 145. Disponível em: http://www.scielo.br/scielo.php?script=sci arttext\&pid=S0104-12902007000100013\&lng=pt\&nrm=iso $\quad$ Acesso em: 06 nov. 2009. doi: 10.1590/S0104-12902007000100013

BLINDER, D. A. et al. Ciência e realidade: ar, água, solo, ecologia e programas de saúde. São Paulo: Atual, 1992. 
BRAGA, B. et al. Introdução à engenharia ambiental. 8. ed. São Paulo: Prentice Hall, 2002.

COISSI, J. Odor de fábrica provoca mal-estar em Brodowski. Folha de S. Paulo. Ribeirão Preto, G4. 20 set. 2009.

DIAS, G. F. Educação ambiental: princípios e práticas. 9. ed. São Paulo: Gaia, 2004.

Fundação Padre Anchieta. Alerta verde: lixo e reciclagem: $1^{\circ}$ e $2^{\circ}$ parte: Desafio do lixo: VÍDEO TV CULTURA (2001). Colorido. 108min. 83seg. 1 DVD.

FERREIRA, L. da C., Encontros e caminhos: formação de educadoras(es) ambientais e coletivos educadores. Brasília: MMA, Diretoria de Educação Ambiental, 2005.

DUARTE, M. Infoescola, navegando e aprendendo. Lixo urbano, 2008. Disponível em:http://www.infoescola.com/meio-ambiente/lixo-urbano/. Acesso em: 26 dez. 2009.

LAURENCE, J. Biologia: ensino médio, volume único. São Paulo: Nova Geração, 2005.

LINHARES, S.; GEWANDSZNAJDER, F. Biologia: volume único. São Paulo: Ática, 2005.

LOPES, S.; ROSSO, S. Biologia: volume único. São Paulo: Saraiva, 2005.

LUTZENBERGER, J. Do jardim ao poder: ecologia. 11. ed. Porto Alegre: L\&PM, 1992.

MUCELIN, C. A.; BELLINI, M. Lixo e impactos ambientais perceptíveis no ecossistema urbano. Sociedade \& Natureza. Uberlândia, v.20, n. 1, p. 111-124, jun. 2008. Disponível em: http://www.seer.ufu.br/index.php/sociedadenatureza/article/viewFile/9355/5732 Acesso em: 06 nov. 2009.

NASCIMENTO, E.F. Educação ambiental para todos. Franca: Ribeirão gráfica e editora, 2007.

OLIVEIRA, M. A. A. L. de. Produtos reciclados fonte de renda e de desenvolvimento social: Projeto, 2002. Disponível em: http://maryannelopes.blogspot.com/2009/02/produtosreciclados-fonte-de-renda-e-de.html Acesso em: 25 fev. 2010.

PAULINO, W. R. Biologia: novo ensino médio. 6. ed. São Paulo: Ática, 2001.

SCARLATO, F. C.; PONTIN, J. A. Do nicho ao lixo: ambiente, sociedade e educação. 6. ed. São Paulo: Atual, 1992.

SOARES, J. L. ,Programas de saúde. São Paulo: Scipione, 1994.

VESENTINI, J. W.; VLACH, V. Geografia crítica: o espaço natural e a ação humana. São Paulo: Ática, 2002. 